\title{
Seasonal forecasts of hydrological drought in the Limpopo basin: Getting the most out of a bouquet of methods.
}

\author{
Mathias Seibert (1) and Patricia Trambauer (2) \\ (1) GFZ Potsdam, Section 5.4 Hydrology, Potsdam, Germany (mathias.seibert@gfz-potsdam.de), (2) Unesco IHE, Delft, \\ Netherlands (p.trambauer@unesco-ihe.org)
}

Droughts are a widespread natural hazard with large socio-economical and environmental impacts. Preparedness to droughts can be enhanced by seasonal drought early warning. When warned several months ahead of a drought event water managers can trigger action plans to mitigate drought and reduce the risk for severe impacts. Seasonal streamflow forecast systems have been dominated by statistical methods in the past. Recently, dynamic physicsbased seasonal forecasts from global climate models have become available operationally. In combination with hydrological models these modern forecast systems have the potential to replace the seasonal statistical forecasts. However, at lead times exceeding 6 months statistical methods might still be useful. In this study we present a forecast scheme for streamflow in the Limpopo basin in Southern Africa, combining statistical methods at longer lead times with a dynamical forecast, a distributed hydrological model forced with the ECMWF seasonal forecast system S4, for shorter lead times ( $<6$ months). The statistical model is set up and tailor-made specifically for drought early warning at a station of interest. The main advantage is that the approach is simple and requires little infrastructure once the model is set up. However, the model does not provide any more information than what it was set up for. This is where the second approach, the dynamical forecast, has its greatest advantage. The model provides a great array of information regarding the catchment status and therefore can be used to forecast a variety of indicators. The skill of the presented systems is higher than climatology (ROC > 0.5) for both methods. There was a large difference in predictability between stations. Yet, the skill in several stations was good. We show that the presented approach is feasible and can provide useful information for drought early warning systems and water managers. 